\title{
Intraligamentary anesthesia - A brief review of an underestimated anesthetic technique
}

\author{
Doris Burtscher ${ }^{1}$ and Daniel Dalla Torre ${ }^{2 *}$ \\ ${ }^{1}$ University Clinic of Prosthetic Dentistry, Medical University Innsbruck, innsbruck, Austria \\ ${ }^{2}$ Private practice, Jaufenstrasse 20, Sterzing, Italy
}

\begin{abstract}
Various anesthetic options are known in the field of dentistry. The most frequently used techniques are the infiltration anesthesia (IA) and the inferior alveolar nerve block (IANB). However, both methods are characterized by a long-lasting action, mostly longer than needed, and possible significant complications like nerve injuries. Moreover, as patients are getting older, cardiovascular and medicinal issues have to be taken into account when dental anesthesia is performed. A less known and used technique is represented by the intraligamentary anesthesia, which has unique characteristics and advatages. This special technique, its effect on the periodontal tissues, advantages and disadvantages including contraindications are discussed in the present paper.
\end{abstract}

\section{Introduction}

A successful pain management through efficient local anesthesia is the basis for every dental therapy. On the one hand, patients expect a painless and comfortable dental treatment, which becomes crucial especially in subjects suffering from dental phobia [1]. On the other hand, the skill of a dentist or oral surgeon himself is often measured by the ability of achieving profound and successful local anesthesia and pain relief. There are different, more or less known options of local anesthesia in the dental area, first of all infiltration anesthesia (IA) as well as the inferior alveolar nerve block (IAN). While IA interrupts the pain perception in the area of injection, the second mentioned technique is related to the innervation area of the mandibular nerve. Indeed, beside the interruption of pain perception, both local anesthetic methods block also the function of sensitive and motor nerves [2]. As a consequence patients experience loss of sensitivity as well as total or partial loss of function of facial muscles and/or the tongue for the duration of the anesthesia [3]. The result is a temporary restriction of patients' daily life with reduced ability in speaking and eating, but also the risk of bite and burn injuries. Moreover, it is well known, that a rare but major complication of IANB is represented by the lesion of the mandibular nerve with possible permanent disturbances of the nerve function [4].

\section{Historical overview}

In order to reduce these undesirable side effects first attempts were made already at the beginning of the 20th century in order to anesthetize single teeth directly without influencing the nerve structures of the surrounding tissues [5]. In 1920 Chompret published his experiences entitling his work "Anesthésie par injections intraligamenteuses" [6] . During the following decades the described technique of intraligamentary anesthesia (ILA) was refined simultaneously to the development of new anesthetical devices. These instruments enabled the injection of the anesthetic solution in the periodontal ligament against the high periodontal tissue resistance (back-pressure) with only little effort by the dentist himself. Meanwhile various injection devices are available, both as manual instrument (as pistol-type, penholder grip syringe or dosing wheel syringe) as well as computer-controlled systems (CCLADS: computer controlled local anesthetic delivery system) [7]. Figure 1 shows an example of a penholder grip syringe armamentarium.

\section{ILA-technique}

All of the mentioned devices are characterized by the same working principle [5]. The ILA starts with needle $(27-30 \mathrm{G}, 0.3-0.4 \mathrm{~mm}$ in diameter) insertion in the periodontal ligament space between the root of the tooth and the alveolar bone. The needle is inserted at an angle of 30-40 degrees in respect to the long axis of the tooth and should reach a subgingival depth of about 2 to $3 \mathrm{~mm}$ in periodontal healthy individuals (Figure 2). At least $0.2 \mathrm{ml}$ anesthetic solution should be applied for each injection site, whereby single rooted teeth should be anesthetized with two injections, multi-rooted teeth with one injection per root. The injection time for the first application should reach at least 20 seconds, whereas every following injection for the same tooth should last few seconds longer. Histologic studies have shown that the anesthetic solution diffuses into the alveolar bone after application, a process that needs time in order to overcome tissue resistance and avoid an overpressure in the periodontal complex. In case of any overhasty injection, extrusion of the respective tooth with a premature contact due to hydraulic forces may be the consequence.

Anesthesia is achieved to the tooth itself but also to the directly surrounding tissues, fundamental especially in case of extractions $[8,9]$. The onset of a successful in anesthesia may be expected after about 40 seconds, the average duration is of about 30 minutes, sufficient for most dental treatments, regardless of conservative, prosthetic or endodontic procedures or extractions. If a longer duration is necessary, re-injection

${ }^{\star}$ Correspondence to: Daniel Dalla Torre, Private practice, Jaufenstrasse 20, Sterzing, Italy, E-mail: chir@dentalclinic-dallatorre.it

Key words: intraligamentary, anesthesia, intraligamental, minimally invasive, ILA

Received: July 14, 2019; Accepted: August 08, 2019; Published: August 12, 2019 


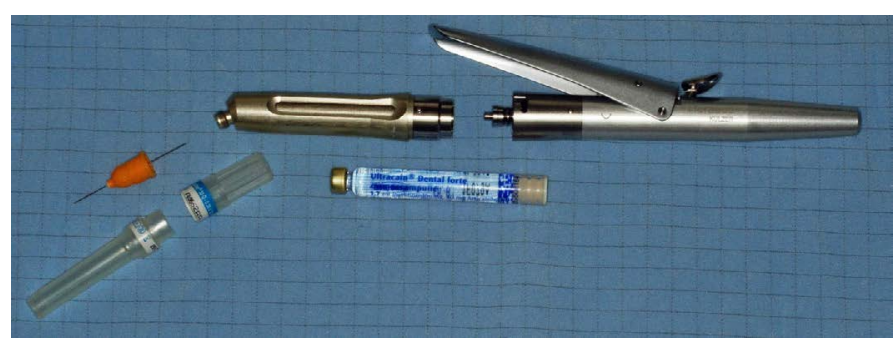

Figure 1. Penholder grip syringe armamentarium

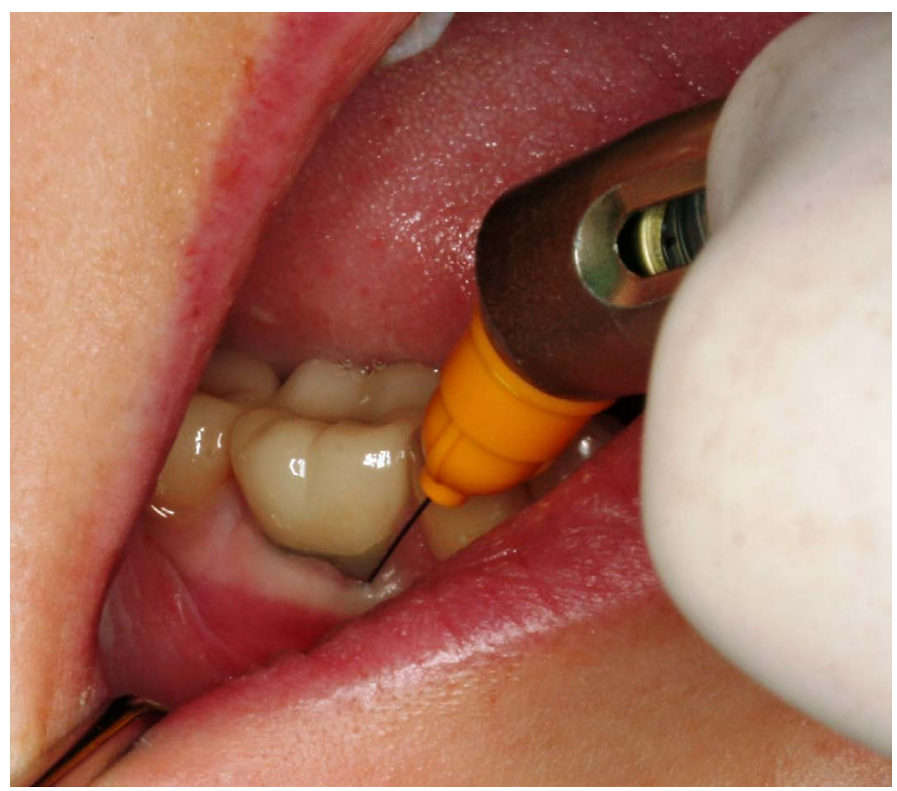

Figure 2. An angle of 30-40 degrees in respect to the long axis

is possible, although paying attention regarding the injection time $(>20$ seconds).

\section{Periodontal effects of ILA}

There is still skepticism regarding the possible negative consequences of ILA on the periodontium. In the last decades several authors conducted animal studies in order to investigate the short- and long-term effect of ILA on the periodontal ligament histologically. Every study described a temporary inflammatory response in the first 24 hours after ILA. However, none of the authors could find a permanent damage of the periodontium after this initial reaction, neither with respect respect to soft tissue (periodontal fibers, gingiva) yet on hard tissue (alveolar bone) [10-13].

Similarly, the possible association between ILA and the occurrence of a dry socket after extraction has been widely studied. No investigation could detect a significant relation between the anesthetic methods and wound healing disorders in terms of dolor post extractionem [14,15].

\section{Undesirable side effects}

Among the described temporary undesirable side effects after intraligamentary injection, postoperative pain due to high pressure during injection as well as tooth extrusion with premature contact are most frequent. Both complications are a consequence of a too fast and too forceful injection. As a result, the anesthetic solution cannot diffuse in the periodontal tissue and the alveolar bone, as described above. As liquids are not compressible, the tooth is pressed out of the alveolar compartment and extruded towards the oral cavity by a "hydraulic leverage" [16]. Occlusal precontacts may be the final result. In summary, these complications are not technique-dependent but operator-dependent, as they can be avoided with accurate consideration of the injection features, especially the injection time.

\section{Advantages of ILA}

Due to the limited anatomical range and the limited duration of action of 30 minutes, the ILA offers the user some advantages both to the patient and the dentist. Postoperative restrictions (speaking, eating, drinking) are missing, patients following a dental treatment under ILA are not restricted regarding their daily life activities or their occupational obligations. Simultaneously, ILA prevents postoperative bite or burn injuries, which can be the consequence of prolonged loss of sensitivity for example after IANB. In addition, the localized anesthetic effect of ILA allows for treatments in different regions (e. g. left and right mandibular molars) in the same session. Since the onset of the anesthetic effect is reached almost immediately after injection, there is no latency between anesthesia and treatment, like it has to be taken into account for IA and IANB. Moreover and in contrast to IANB, there is no risk for nerve injuries by intraligamentary injections [17].

Finally, ILA allows for a significant reduction of the total amount of both anesthetic solution and vasoconstrictor supplement compared to other anesthetic methods. Simultaneously, accidental intravascular application is avoided. Due to these characteristics, intraligamentary anesthesia is advantageous especially in the treatment of multimorbid "high-risk patients" (e. g. patients with cardiovascular disease or anticoagulation) [8].

\section{Contraindications}

Given the fact, that according to the present literature negative long term effects of ILA may be excluded, there are still some contraindications that must be taken into account. In the late 80 s Rahn et al. found a potentially high rate of bacteremia of $61 \%$ in patients treated with ILA $[18,19]$. They could decrease significantly this rate by a preoperative mouthwash with chlohexidine for 30 seconds. However, ILA represents still a hazardous method for patients with the risk of Endocarditis or immunosuppressed patients. Moreover, in case of a profound marginal periodontitis or in teeth with a sclerotic periodontal gap, the usefulness of ILA is reduced and alternative anesthetic techniques (IANB, IA) are recommended.

\section{Conclusion}

In summary, intraligamentary anesthesia can rated as efficient as infiltration anesthesia or inferior alveolar nerve block. Numerous investigations have demonstrated the feasibility of ILA for most dental routine treatments, whereas the patients additionally benefit from the mentioned advantages of this technique. Accordingly, as minimally invasive method of dental anesthesia represents a clear benefit for both practitioners and patients.

\section{Funding information}

There was no funding regarding the present work.

\section{Competing interests}

The authors declare that there are no competing interests.

\section{References}

1. Aggarwal K, Lamba AK, Faraz F, Tandon S, Makker K (2018) Comparison of anxiety and pain perceived with conventional and computerized local anesthesia delivery systems for different stages of anesthesia delivery in maxillary and mandibular nerve blocks. J Dent Anesth Pain Med 18: 367-373. [Crossref] 
2. Hawkins JM, Moore PA (2002) Local anesthesia: advances in agents and techniques. Dent Clin North Am 46: 719-732. [Crossref]

3. Sambrook PJ, Goss AN (2011) Severe adverse reactions to dental local anaesthetics: prolonged mandibular and lingual nerve anaesthesia. Aust Dent $J$ 56: 154-159. [Crossref]

4. Alhassani AA, AlGhamdi AS (2010) Inferior alveolar nerve injury in implant dentistry: diagnosis, causes, prevention, and management. J Oral Implantol 36: 401-407. [Crossref]

5. Meechan JG (1992) Intraligamentary anaesthesia. J Dent 20: 325-332. [Crossref]

6. Chompret L (1920) Anesthésie par injections intraligamenteuses. Rev Stomatol Chir Maxillofac 6: 309-312.

7. Baghlaf K, Elashiry E, Alamoudi N (2018) Computerized intraligamental anesthesia in children: A review of clinical considerations. J Dent Anesth Pain Med 18: 197-204. [Crossref]

8. Kammerer PW, Adubae A, Buttchereit I, Thiem DGE2, Daubländer M, et al. (2018) Prospective clinical study comparing intraligamentary anesthesia and inferior alveolar nerve block for extraction of posterior mandibular teeth. Clin Oral Investig 22: 14691475. [Crossref]

9. Thiem DGE, Schnaith F, Van Aken CME, Köntges A, Kumar VV, et al. (2018) Extraction of mandibular premolars and molars: comparison between local infiltration via pressure syringe and inferior alveolar nerve block anesthesia. Clin Oral Investig 22: 1523-1530. [Crossref]
10. Fuhs QM, Walker WA, Gough RW, Schindler WG, Hartman KS. The periodontal ligament injection: histological effects on the periodontium in dogs. J Endod 9: 411415. [Crossref]

11. Galili D, Kaufman E, Garfunkel AA, Michaeli Y (1984) Intraligamentary anesthesia--a histological study. Int J Oral Surg 13: 511-516. [Crossref]

12. Walton RE, Garnick JJ (1982) The periodontal ligament injection: histologic effects on the periodontium in monkeys. J Endod 8: 22-26. [Crossref]

13. Froum SJ, Tarnow D, Caiazzo A, Hochman MN (2000) Histologic response to intraligament injections using a computerized local anesthetic delivery system. A pilot study in mini-swine. J Periodontol 71: 1453-1459. [Crossref]

14. Tsirlis AT, Iakovidis DP, Parissis NA (1992) Dry socket: frequency of occurrence after intraligamentary anesthesia. Quintessence Int 23: 575-577. [Crossref]

15. Endo T, Gabka J, Taubenheim L (2008) Intraligamentary anesthesia: benefits and limitations. Quintessence Int 39: 15-25. [Crossref]

16. Huber HP, Wilhelm-Höft C (1988) [Effects of intraligamentous anesthesia on tooth mobility]. Dtsch Zahnarztl Z 43: 313-316. [Crossref]

17. Kammerer PW, Schiegnitz E, von Haussen T, Shabazfar N, Kämmerer P, et al. (2014) Clinical efficacy of a computerised device (STA ) and a pressure syringe (VarioJect INTRA ) for intraligamentary anaesthesia. Eur J Dent Educ 19: 16-22. [Crossref]

18. Rahn R, Frenkel G, Atamni F, Shah PM, Schafer V (1987) Bacteremia after intraligamental anesthesia. Schweiz Monatsschr Zahnmed 97: 859-863. [Crossref]

19. Rahn R, Frenkel G, Shah PM, Schafer V (1988) Bacteremia following intraligament anesthesia. Dtsch Z Mund Kiefer Gesichtschir 12: 272-275. [Crossref]

Copyright: (2019 Burtscher D. This is an open-access article distributed under the terms of the Creative Commons Attribution License, which permits unrestricted use, distribution, and reproduction in any medium, provided the original author and source are credited. 